\title{
Proteolysis of monocyte CD14 by human leukocyte elastase inhibits lipopolysaccharide-mediated cell activation
}

\author{
Karine Le-Barillec, Mustapha Si-Tahar, Viviane Balloy, and Michel Chignard \\ Unité de Pharmacologie Cellulaire, Unité Associée IP/Institut National de la Santé et de la Recherche Médicale \\ 485, Institut Pasteur, 75015 Paris, France \\ Address correspondence to: Karine Le-Barillec, Unité de Pharmacologie Cellulaire, \\ Unité Associée IP/Institut National de la Santé et de la Recherche Médicale 485, Institut Pasteur, 25, \\ rue du Dr Roux, F-75724 Paris cédex 15, France. Phone: 33-1-45-68-86-88; Fax: 33-1-45-68-87-03; E-mail: k3lebrec@pasteur.fr
}

Mustapha Si-Tahar's present address is: Epithelial Pathobiology Research Unit, Emory University School of Medicine, Atlanta, Georgia, 30322 USA.

Received for publication November 11, 1998, and accepted in revised form February 11, 1999.

\begin{abstract}
Human leukocyte elastase (HLE), a polymorphonuclear neutrophil (PMN) serine proteinase, is proteolytically active on some membrane receptors at the surface of immune cells. The present study focused on the effect of HLE on the expression of CD14, the main bacterial lipopolysaccharide (LPS) receptor at the surface of monocytes. HLE exhibited a time- and concentration-dependent downregulatory effect on CD14 surface expression. A 30-minute incubation of $3 \mu \mathrm{M}$ HLE was required to display $95 \%$ disappearance of the receptor. This downregulation resulted from a direct proteolytic process, not from a shedding consecutive to monocyte activation as observed upon challenge with phorbol myristate acetate (PMA). To confirm that CD14 is a substrate for HLE, this enzyme was incubated with recombinant human CD14 $\left(\mathrm{M}_{\mathrm{r}} \sim 57,000\right)$, and proteolysis was further analyzed by immunoblot analysis. Cleavage of the CD14 molecule was directly evidenced by the generation of short-lived fragments $\left(M_{r} \sim 47,000\right.$ and $30,000)$. As a consequence of the CD14 proteolysis, a decrease in the responsiveness of monocytes to LPS was observed, as assessed by measuring tumor necrosis factor- $\alpha$ (TNF- $\alpha$ ) formation. This inhibition was only observed with $1 \mathrm{ng} / \mathrm{ml}$ of LPS, i.e., when only the CD14-dependent pathway was involved. At a higher LPS concentration, such as $10 \mu \mathrm{g} / \mathrm{ml}$, when CD14-independent pathways were operative, this inhibition was overcome. The direct proteolysis by HLE of the membrane CD14 expressed on monocytes illustrates a potential anti-inflammatory effect of HLE through inhibition of LPS-mediated cell activation.

J. Clin. Invest. 103:1039-1046 (1999).
\end{abstract}

\section{Introduction}

Although polymorphonuclear neutrophils (PMNs) are major contributors to host defense against infectious agents, they are a double-edged sword (1). PMNs are necessary to contend against infections through phagocytosis and destruction of microorganisms, but paradoxically, they are also important effectors of inflammation, particularly through proteolytic enzymes that they release into the extracellular space during phagocytosis (2). One of these enzymes is human leukocyte elastase (HLE), a serine proteinase that has been linked to the pathogenesis of a variety of inflammatory diseases, including different lung pathologies such as bronchiectasis, cystic fibrosis, acute respiratory distress syndrome (ARDS), bronchitis, and emphysema $(3,4)$. This is the consequence of extensive proteolysis of extracellular matrix molecules such as collagens, fibronectin, laminin, proteoglycans, and more importantly elastin, an abundant component of the lung parenchyma (5). HLE can also affect the epithelium and endothelium by increasing cellular permeability $(6,7)$ and, more dramatically, by inducing cell lysis $(8,9)$. Moreover, HLE stimulates secretion from airway gland cells (10), activates granu-locyte-macrophage colony-stimulating factor
(GM-CSF) release (11), and induces interleukin-8 gene expression (12) in bronchial epithelial cells. Thus, HLE has a broad spectrum of proinflammatory activities.

In contrast, several recent reports have suggested HLE's possible involvement in anti-inflammatory processes. For example, HLE has been shown to decrease the adhesion of PMNs through its binding to the integrin $\alpha_{M} \beta_{2}$ (13). Our group has also previously demonstrated that HLE inhibits thrombin-induced cell activation through a specific proteolysis and deactivation of the seven-transmembrane domain thrombin receptor (14), a receptor known to be involved not only in hemostasis and thrombosis but also in inflammation (15). In addition, HLE may potentially be involved in the downregulation of inflammation through the cleavage of a number of cellsurface molecules. For instance, HLE has been shown to reduce the surface expression of different receptors such as CD2, CD4, and CD8 on lymphocytes (16), and CD16 (17), CD43 (18), and the 75-kDa form of the tumor necrosis factor- $\alpha$ (TNF- $\alpha$ ) receptor (19) on PMNs.

The potential physiopathological importance of these proteolytic effects of HLE at the surface of immune cells prompted us to examine the possibility that mononuclear phagocytes could also be a target for this enzyme. 
a

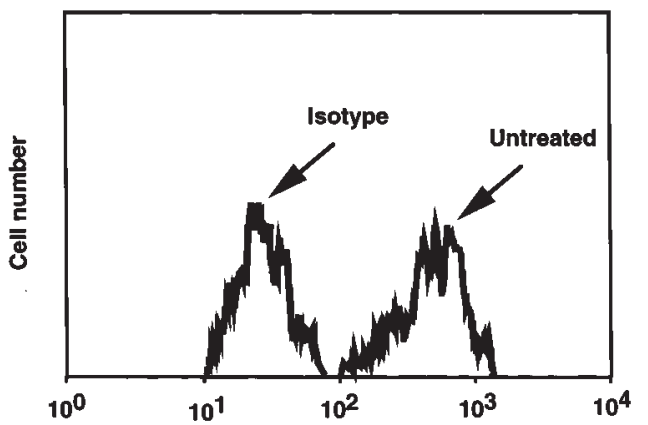

$b$

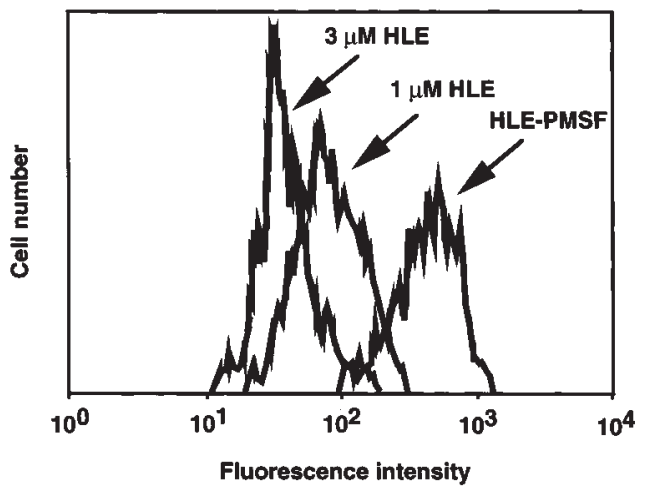

Figure 1

Effect of HLE on the surface expression of CD14 on human monocytes. Monocytes were treated with 1 or $3 \mu \mathrm{M}$ HLE or $3 \mu \mathrm{M}$ HLE-PMSF for 30 min at $37^{\circ} \mathrm{C}$, and reactions were stopped as described in Methods. Binding of the MY4 antibody or a matched isotype was then analyzed by flow cytometry. (a) Nontreated cells were labeled with the MY4 antibody (Untreated) or a matched IgG2b (Isotype). (b) Treated cells (as indicated) were labeled with MY4 antibody. Fluorescence tracings are representative of three distinct experiments. HLE, human leukocyte elastase.

Monocytes and macrophages are of utmost interest because they are active participants in the first line of defense against infection by killing pathogens and scavenging dead cells. Indeed, monocytes and macrophages not only function as mere phagocytic cells, but they are also highly sophisticated, flexible cells that produce an array of mediators and play a role in immunity, inflammation, tissue repair, and blood coagulation (20).

CD14, a $55-\mathrm{kDa}$ glycoprotein that is anchored by glycosylphosphatidylinositol (GPI) and expressed predominantly at the surface of monocytes and macrophages, is the main receptor for lipopolysaccharide (LPS), a glycolipid of the outer membrane of Gram-negative bacteria (21). Activation of monocytes and macrophages through CD14 leads to the formation of numerous inflam matory mediators implicated in diseases such as rheumatoid arthritis, sepsis, or ARDS - different pathologies in which HLE is also present. At least two studies led us to consider the mononuclear phagocytes, and more specifically the membrane CD14 molecule, as a putative target for HLE. First, Campbell (22) reported that HLE binds to specific sites on alveolar macrophages; then Bazil and Strominger (23) demonstrated that exposure of monocytes to phorbol myristate acetate (PMA) induced a loss of the surface expression of CD14. This effect was shown to be associated with a concomitant release of a soluble form of this antigen (sCD14), a process likely mediated by serine proteinases because specific inhibitors prevented this receptor from shedding. These considerations led us to examine a potential effect of HLE on the CD14 expressed on monocytes, an effect that may occur at sites of inflammation where both activated neutrophils and mononuclear phagocytes are present.

\section{Methods}

Reagents and antibodies. Blood was obtained from the Etablissement de Transfusion Sanguine (Paris, France). LPS from Escherichia coli 055:B5 (Sigma Chemical Co., St. Louis, Missouri, USA) was dissolved and sonicated $1 \mathrm{~min}$ in sterile saline solution and frozen in aliquots. Eglin $\mathrm{C}$ was generously provided by H.P. Schnebli (Novartis, Basel, Switzerland). PMA, phorbol 12,13-didecanoate (PDD), and the proteinase inhibitor PMSF were obtained from Sigma Chemical Co. Phosphatidylinositolphospholipase C (PI-PLC) from Bacillus cereus was purchased from Boehringer Mannheim (Mannheim, Germany). Control monoclonal mouse $\mathrm{IgG}_{2 \mathrm{~b}}$ antibody was from Biodesign International (Kennebunk, Maine, USA), and FITC-conjugated goat anti-mouse IgG antibody was from DAKO (Copenhagen, Denmark). Reagents for SDS-PAGE were purchased from Bio-Rad Laboratories Inc. (Hercules, California, USA). Nitrocellulose membranes $(0.45-\mu \mathrm{m}$ pores) were from Schleicher and Schuell (Dassel, Germany). Recombinant human CD14 in serum-free culture supernatant of CHO-transfectants was purchased from Biometec (Greifswald, Germany). A peroxidase-linked donkey anti-rabbit Ig antibody was from Amersham (Little Chalfont, UK). Anti-human CD14 antibodies used in this study included a rabbit anti-CD14 polyclonal antibody kindly supplied by P. Detmers (Rockefeller University, New York, New York, USA) and MY4, a murine monoclonal anti-CD14 antibody obtained from Coulter Corp. (Miami, Florida, USA).

HLE was purified as described previously (24). To block the catalytic site of HLE, the purified proteinase was incubated for $60 \mathrm{~min}$ at $25^{\circ} \mathrm{C}$ with $1.25 \mathrm{mM}$ PMSF, and the mixture was subsequently dialyzed to remove the free inhibitor. PMSF-treated HLE was shown to be proteolytically inactive by testing the lack of hydrolysis of its specific synthetic substrate, $\mathrm{N}$-succinyl(Ala) ${ }_{3}$-p-nitroanilide (Sigma Chemical Co.).

Purification of buman monocytes. Monocytes were purified from blood collected on heparin and acid citrate dextrose. Blood (2

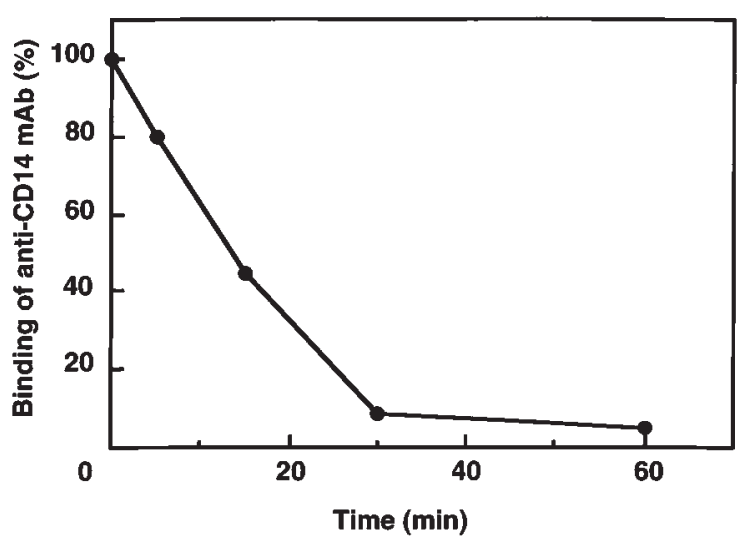

Figure 2

Time course of reduction by HLE of the surface expression of CD14 on human monocytes. Monocytes were treated with $3 \mu \mathrm{M}$ HLE for various time periods at $37^{\circ} \mathrm{C}$. CD14 expression was analyzed by flow cytometry using the MY4 antibody. The binding of MY4 is expressed as the percentage of the control value obtained with nontreated cells. Results represent one experiment out of two obtained from different donors. 

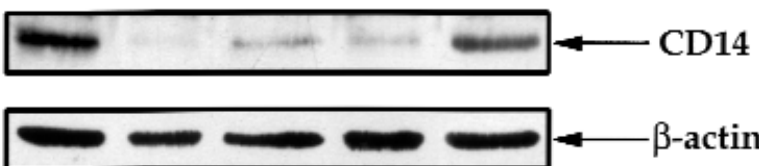

NS HLE PI-PLC PMA PDD

Figure 3

Immunoblot analysis of CD14 expression by human monocytes. Monocytes were untreated (NS) or treated with $3 \mu \mathrm{M} \mathrm{HLE}, 0.6 \mathrm{U} / \mathrm{ml} \mathrm{PI-PLC,} 15$ $\mathrm{nM}$ PMA, or $15 \mathrm{nM}$ PDD for $30 \mathrm{~min}$ at $37^{\circ} \mathrm{C}$. Reactions were stopped with $20 \mu \mathrm{M}$ eglin $\mathrm{C}$, and monocytes were immediately solubilized with Triton/SDS. After SDS-PAGE on $10 \%$ acrylamide gels and transfer to nitrocellulose membranes, samples were probed with a polyclonal anti-CD14 antibody. In addition, the same samples were probed with an anti- $\beta$-actin antibody to control the equal loading of the different wells. Relative molecular mass was calculated with respect to calibration-standard proteins included in the gel. PDD, phorbol 12,13-didecanoate; PI-PLC, phosphatidylinositol-phospholipase C; PMA, phorbol myristate acetate.

vol) was mixed with $3 \%$ (wt/vol) dextran in saline solution (1 $\mathrm{vol}$ ), and erythrocytes were allowed to sediment for $30 \mathrm{~min}$. The leukocyte-rich supernatant was removed and loaded on FicollPaque gradients (Pharmacia Biotech AB, Uppsala, Sweden). After centrifugation at $300 \mathrm{~g}$ for $45 \mathrm{~min}$ at $25^{\circ} \mathrm{C}$, peripheral blood mononuclear cells (PBMCs) were collected and washed with RPMI-1640 medium containing antibiotics (GIBCO BRL, Paisley, Scotland). After centrifugation at $300 \mathrm{~g}$ for $10 \mathrm{~min}$ at $25^{\circ} \mathrm{C}$, the pellet was resuspended in RPMI-1640 medium with $3 \%$ (vol/vol) FCS (Boehringer Mannheim) to a density of $4 \times 10^{6}$ cells $/ \mathrm{ml}$. Monocytes were separated from lymphocytes by allowing monocytes to adhere to plastic dishes (Corning-Costar Corp., Cambridge, Massachusetts, USA) for $1 \mathrm{~h}$ at $37^{\circ} \mathrm{C}$. After removal of nonadherent cells, monocytes were washed again with RPMI-1640 medium. When required, the amount of cell proteins in each well was evaluated using the BCA Protein Assay from Pierce Chemical Co. (Rockford, Illinois, USA).

TNF- $\alpha$ and CD14 concentrations measurement by ELISA. TNF- $\alpha$ and CD14 concentrations in the supernatant of treated monocytes were determined as described previously (25) and by using a commercial sandwich enzyme immunoassay according to the manufacturer's protocol (ICN Radiochemicals Inc., Costa Mesa, California, USA), respectively.

Flow cytometry analysis. At the end of the incubation periods of monocytes under various conditions, reactions were stopped by addition of $20 \mu \mathrm{M}$ eglin C, an inhibitor of HLE. Cells were then washed twice with HBSS (GIBCO BRL) and incubated with 1.5 $\mathrm{ml}$ of cold HBSS containing $0.1 \%$ (wt $/ \mathrm{vol}$ ) BSA. Plates were then left on ice for $15 \mathrm{~min}$ to facilitate cell detachment. Then, cells were resuspended by vigorous pipetting, centrifuged at $300 \mathrm{~g}$ for $10 \mathrm{~min}$ at $4^{\circ} \mathrm{C}$, and fixed with $1 \%$ (vol/vol) formaldehyde for 30 $\mathrm{min}$ at room temperature. After fixation, cells were added to conical bottom 96-well plastic plates (Nunc A/S, Roskilde, Denmark) at $1.5 \times 10^{5}$ cells per well. Next, plates were centrifuged at $80 \mathrm{~g}$ for $5 \mathrm{~min}$ at $4^{\circ} \mathrm{C}$, and monocytes were subsequently incubated with MY4 $(1 \mu \mathrm{g} / \mathrm{ml})$ or with matched $\operatorname{IgG}_{2 \mathrm{~b}}$ control antibody for $30 \mathrm{~min}$ at $4^{\circ} \mathrm{C}$. Cells were centrifuged again at $80 \mathrm{~g}$ for $5 \mathrm{~min}$ at $4^{\circ} \mathrm{C}$ and washed twice with HBSS before incubation for $30 \mathrm{~min}$ at $4^{\circ} \mathrm{C}$ with the FITC-labeled anti-IgG antibody $(5 \mu \mathrm{g} / \mathrm{ml})$. Finally, monocytes were centrifuged and washed as described above and resuspended in the same buffer.

Samples were analyzed using a FACScan cytometer (Becton Dickinson Immunocytometry Systems, Mountain View, California, USA). Binding of MY4 antibody to its specific CD14 epitope at the surface of monocytes was expressed as the percentage of the median fluorescence intensity over control values measured on untreated cells after subtraction of the background bind- ing, which was measured with the control isotype antibody.

SDS-PAGE and immunoblot analysis. At the end of the exposure of monocytes to HLE in plastic dishes, eglin $\mathrm{C}$ was added to block the enzymatic activity. Supernatants were removed and monocytes were solubilized as described previously (26); disulfide bonds were reduced by adding $5 \%$ (vol/vol) 2-mercaptoethanol. SDS-PAGE was subsequently performed according to the Laemmli procedure (27), using $10 \mu \mathrm{g}$ of total monocyte proteins.

Electrophoresis was performed after loading each well on a $10 \%$ acrylamide gel. Proteins were electrotransferred to nitrocellulose membranes (26) and probed by the rabbit polyclonal anti-CD14 antiserum diluted 1:1,000. Then membranes were probed with an anti-rabbit IgG, horseradish peroxidase-linked donkey antibody diluted 1:2,000, washed, and subsequently incubated with ECL detection reagents (Amersham) before exposure to Kodak X-Omat AR films (Kodak-Pathé, Paris, France). For $\mathrm{M}_{\mathrm{r}}$ determinations, polyacrylamide gels were calibrated using standard proteins (Bio-Rad Laboratories Inc.) with $\mathrm{M}_{\mathrm{r}}$ within the range of 14,400 to 200,000 .

Statistics. Results are expressed as mean \pm SEM for the indicated number of independently performed experiments. Statistical significance between the different values was analyzed by the Student's $t$ test for unpaired data with a threshold of $P \leq 0.05$.

\section{Results}

Effect of HLE on the surface expression of CD14 on human monocytes. An alteration of CD14 expression by the PMN serine proteinase HLE was evaluated by flow cytometry analysis using the MY4 monoclonal antibody. As shown in Figure $1 a$, the mean value of the median fluorescence intensity (MFI) was $302.2 \pm 124.7$ for MY4 vs. $27.2 \pm 2.6$ for the control IgG, indicating a strong expression of CD14 at the surface of monocytes $(n=3)$. When these cells were incubated for 30 minutes with two different concentrations of HLE, 1 and $3 \mu \mathrm{M}$, a significant concentration-dependent decrease of the expression of this monocyte-associated antigen was observed (Figure $1 b$ ). Thus, MFI was $72.3 \pm$ 15.9 and $45.8 \pm 12.9$ for 1 and $3 \mu \mathrm{M}$ HLE, respectively $(n=$ $3)$. By contrast, no decrease in the level of CD14 expression was observed after a 30 -minute exposure to $3 \mu \mathrm{M}$ PMSFinactivated HLE, the fluorescence intensity being the same

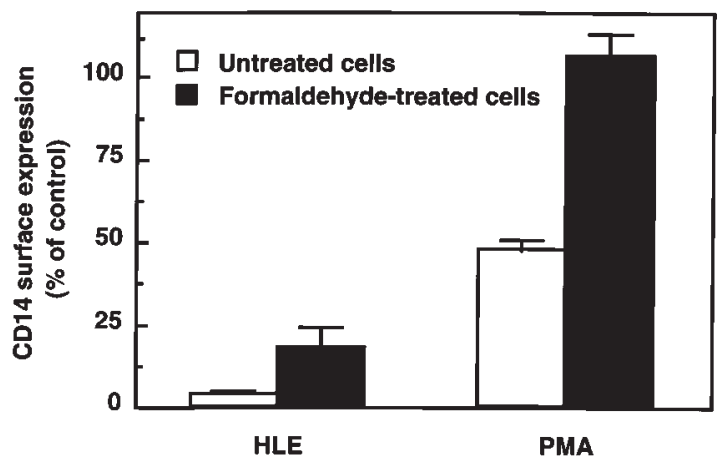

Figure 4

Effect of HLE on the modulation of CD14 surface expression after formaldehyde treatment of monocytes. Monocytes were fixed or not with $1 \%$ formaldehyde for $10 \mathrm{~min}$ at room temperature, and the fixation process was neutralized with $12 \mathrm{mM} \mathrm{NH}_{4} \mathrm{Cl}$. After washing, cells were incubated with $3 \mu \mathrm{M} \mathrm{HLE}$ or $15 \mathrm{nM}$ PMA for $30 \mathrm{~min}$ at $37^{\circ} \mathrm{C}$; at the end of the reaction, $20 \mu \mathrm{M}$ eglin $\mathrm{C}$ was added. Binding of the MY4 anti-CD14 antibody is expressed as the percentage of control values obtained with nontreated cells. Results are means \pm SEM of three experiments. 


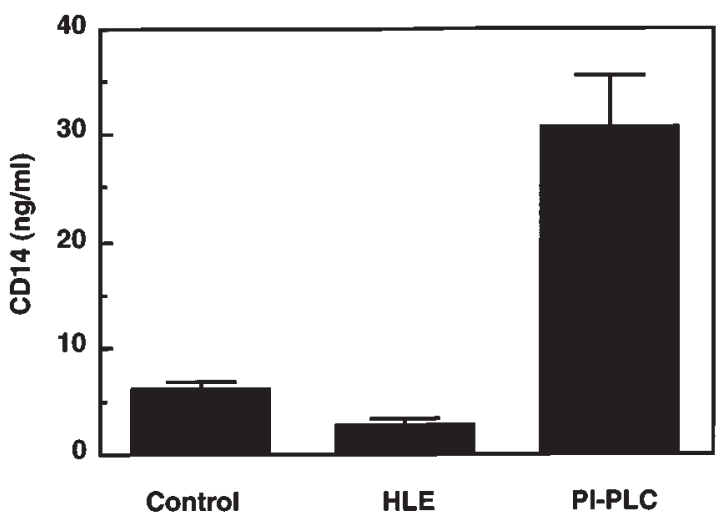

Figure 5

Measurements of CD14 in the extracellular medium of HLE-treated monocytes. Monocytes were treated with $3 \mu \mathrm{M}$ HLE or $0.6 \mathrm{U} / \mathrm{ml} \mathrm{PI-PLC}$ for $30 \mathrm{~min}$ at $37^{\circ} \mathrm{C}$; at the end of the reaction, $20 \mu \mathrm{M}$ eglin $\mathrm{C}$ was added. The extracellular medium was then analyzed for CD14 by ELISA. Data are means \pm SEM of four to seven experiments with different donors.

as for untreated monocytes (MFI $=323.1 \pm 114.1 ; n=3)$. The kinetics of disappearance of the surface expression of CD14 (Figure 2) showed that after a 15-minute exposure of the cells to HLE, values dropped to $\approx 40 \%$ of the initial value and to $\approx 95 \%$ by 30 minutes. Note that $3 \mu \mathrm{M}$ HLE did not trigger a cytotoxic effect, as determined by the lack of significant lactate dehydrogenase release in the medium at the end of the incubation period. At this stage, several possible mechanisms could account for the loss of CD14 from the cell surface: (a) CD14 was internalized; (b) HLE stimulated monocytes with, as a consequence, the activation of an endogenous protease that secondarily induced the shedding of CD14 in the extracellular medium; and (c) HLE directly removed the CD14 molecule from the cell surface through a proteolytic process. Experiments were therefore performed to elucidate which mechanism was specifically involved.

Immunoblot analysis of CD14 expression by buman monocytes. Figure 3 illustrates an immunoblot analysis of monocyte-associated CD14 upon different cell treatments. Considering untreated cells, the antigen runs as a major band with $M_{\mathrm{r}} \sim 57,000$. As a positive control, experiments were performed with PI-PLC, an enzyme that specifically removes GPI-anchored proteins from the cell surface (28); as expected, a strong reduction in the expression of cell-associated CD14 was observed. Another positive control was performed using PMA, which is known to trigger the shedding of membrane CD14 through monocyte endogenous proteinases (23). Here again, the CD14 band was not detected. By contrast, an inactive phorbol analogue of PMA, PDD, had no effect. Monocyte treatment with $3 \mu \mathrm{M}$ HLE led to a complete loss of the CD14 antigen. Equal loading of the different samples was demonstrated by probing transferred membranes with an anti- $\beta$-actin antibody. This absence of CD14 recovery from HLE-treated monocytes thus allowed us to rule out a possible internalization as a putative mechanism for its reduced cell-surface expression.

Effect of HLE on the modulation of CD14 surface expression after formaldebyde treatment of monocytes. To exclude a
CD14 shedding resulting from an intracellular pathway triggered by HLE acting on another membrane structure, monocytes were fixed with $1 \%$ formaldehyde before any treatment. As shown in Figure 4, activation of fixed cells with 15 nM PMA resulted in a total lack of CD14 shedding, as evaluated by flow cytometry analysis. As expected, nonfixed cells responded to PMA with a $58.7 \pm$ $3.9 \%$ loss of the CD14 surface expression. These data clearly indicate that formaldehyde treatment hampered any CD14 shedding due to intracellular activation pathways, as is the case with PMA (23). By contrast, when monocytes fixed with formaldehyde were subsequently treated with $3 \mu \mathrm{M}$ HLE, analysis of MY4 binding still revealed a strong reduction of the CD14 molecule expression, with a value comparable to that observed upon HLE treatment of nonfixed cells. Under the conditions of fixation with formaldehyde, the CD14 surface expression was thus $18.4 \pm 5.8 \%$ of the control value. Altogether, the foregoing experiments established that HLE caused neither internalization nor shedding through activation of monocytes, but pointed out a direct proteolysis of CD14 by this serine proteinase.

Measurements of CD14 in the extracellular medium of HLEtreated monocytes. Using an ELISA, experiments were next performed to estimate the quantity of CD14 released into the extracellular reaction medium of monocytes incubated with HLE. As shown in Figure 5, CD14 was spontaneously released from nontreated monocytes during the incubation period, with a basal recovery of $6.1 \pm 0.8 \mathrm{ng} / \mathrm{ml}(n=7)$. After PI-PLC treatment, $30.5 \pm 5.1 \mathrm{ng} / \mathrm{ml} \mathrm{CD14}$ was detected. By contrast, after HLE treatment CD14 was barely detectable in the extracellular medium, with a mean value of $2.6 \pm 0.8$ $\mathrm{ng} / \mathrm{ml}$. A possible explanation for this result was that HLE cleaved membrane-associated CD14 into fragments too small to be detected by the immunoassay.

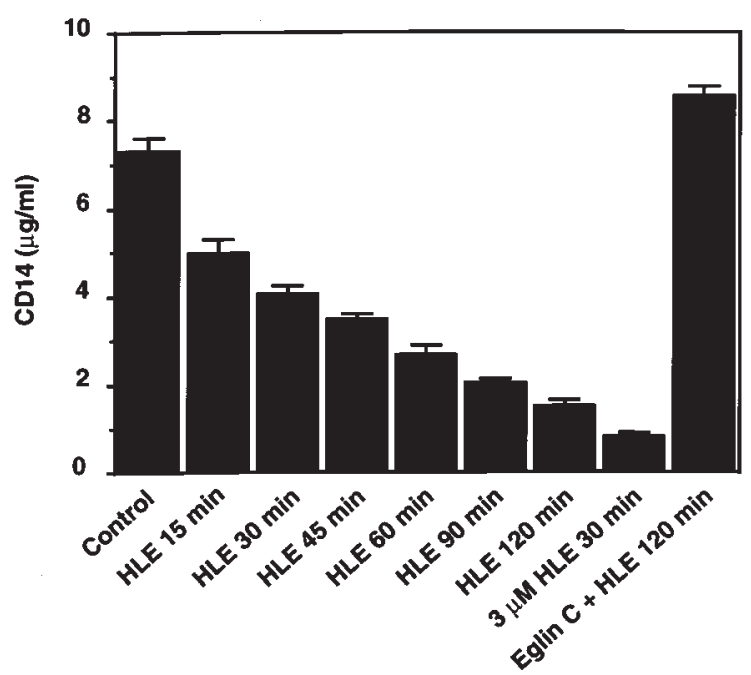

Figure 6

Time course of the disappearance of recombinant CD14 upon incubation with HLE. Recombinant CD14 $(0.25 \mu \mathrm{M})$ was incubated with 500 $\mathrm{nM}$ or $3 \mu \mathrm{M}$ (where indicated) $\mathrm{HLE}$ for various time periods at $37^{\circ} \mathrm{C}$. A mixture of $20 \mu \mathrm{M}$ eglin C and $500 \mathrm{nM}$ HLE was incubated for $2 \mathrm{~h}$ under the same conditions. Reactions were stopped with $20 \mu \mathrm{M}$ eglin $\mathrm{C}$, and samples were next analyzed for CD14 by ELISA. Data are means \pm SEM of three distinct experiments. 
Figure 7

Immunoblot analysis of the time course of HLE-treated recombinant CD14. Recombinant CD14 (0.25 $\mu \mathrm{M})$ was incubated with $500 \mathrm{nM}$ or $3 \mu \mathrm{M}$ (where indicated) HLE for various time periods at $37^{\circ} \mathrm{C}$. A mixture of $20 \mu \mathrm{M}$ eglin $\mathrm{C}$ and $500 \mathrm{nM}$ HLE was incubated for $2 \mathrm{~h}$ under the same conditions. Reactions were stopped with $20 \mu \mathrm{M}$ eglin C, and samples were processed for CD14 immunoblot analysis using a $15 \%$ polyacrylamide gel. Relative molecular masses were calculated with respect to calibration-standard proteins included in the gel. (a) Membrane exposed for $1 \mathrm{~min}$; (b) same membrane exposed for $2 \mathrm{~h}$.

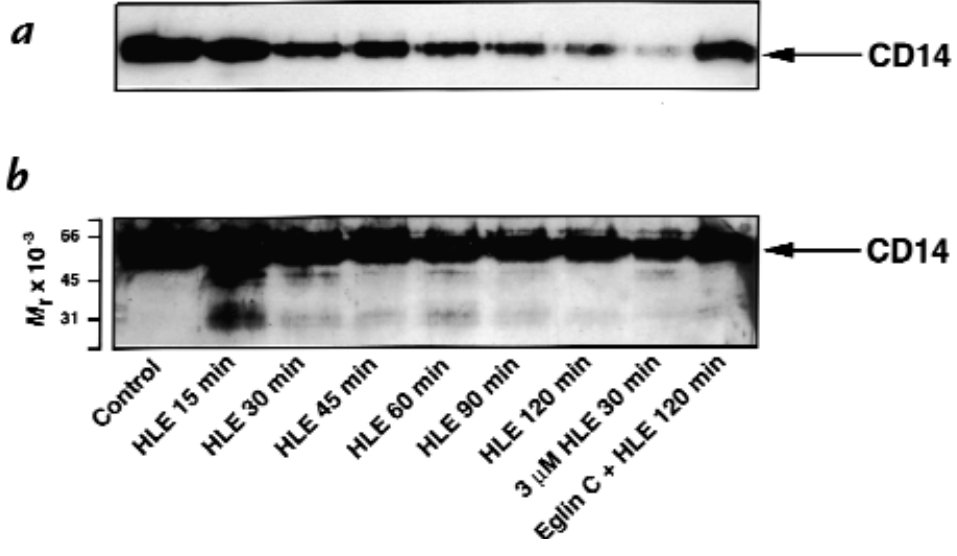

Effect of HLE on soluble recombinant CD14. To check the above-mentioned hypothesis, $0.25 \mu \mathrm{M}$ recombinant CD14 was reacted with $500 \mathrm{nM}$ HLE for different time intervals between 15 minutes and 2 hours (Figure 6). A time-dependent decrease of the immunoreactive CD14 was observed by ELISA, with a final detectable concentration of $1.5 \pm 0.2 \mu \mathrm{g} / \mathrm{ml}$ after a 2 -hour incubation. This must be compared with $7.3 \pm 0.3 \mu \mathrm{g} / \mathrm{ml}$, the concentration detected in untreated samples of recombinant CD14. A treatment with $3 \mu \mathrm{M}$ HLE for 30 minutes reduced the concentration of CD14 to $0.8 \pm 0.1 \mu \mathrm{g} / \mathrm{ml}$, whereas eglin $C$ prevented any disappearance of the initial CD14 amount. Thus, these data indicate that CD14 removed by HLE from the monocyte membrane is likely rapidly degraded into short peptides. In fact, this was directly demonstrated by immunoblot analysis of this same incubation of recombinant CD14 with HLE. As shown in Figure $7 a$, after HLE treatment the recombinant CD14 band disappeared in a time-dependent manner. The kinetic profile was strictly comparable with that obtained by ELISA (Figure 6). Under these conditions, fragments with lower $M_{r}$ could be detected on films exposed for a longer period of time. As depicted in Figure $7 b$, two bands with $\mathrm{M}_{\mathrm{r}} \sim 47,000$ and 30,000 were revealed at 15 minutes. Interestingly, these two fragments progressively disappeared as the time of exposure to HLE increased.

Inhibition by HLE of TNF- $\alpha$ synthesis by LPS-activated buman monocytes. TNF- $\alpha$ is one of the major proinflammatory and pleiotropic cytokines secreted largely by mononuclear cells (29). As shown in Figure 8a, preincubation of human monocytes with $1 \mu \mathrm{M}$ HLE for 30 minutes substantially reduced TNF- $\alpha$ formation triggered by $1 \mathrm{ng} / \mathrm{ml} \mathrm{LPS}$, with $5.9 \pm 2.0 \mathrm{vs} .8 .6 \pm 1.1 \mathrm{pg} / \mu \mathrm{g}$ protein in the presence and absence of the neutrophil proteinase, respectively $(n=3, P<0.05)$. This effect of HLE was concentration-dependent, with a much more marked effect upon pretreatment with $3 \mu \mathrm{M}$. Under the latter condition, TNF- $\alpha$ concentration was reduced to $2.2 \pm 0.9 \mathrm{pg} / \mu \mathrm{g}$ protein $(n=3, P<0.05)$, a concentration not significantly different from that recovered from resting cells. Again, the proteolytic activity of HLE was required for such an inhibitory activity, as shown by the lack of modification in TNF- $\alpha$ formation when monocytes were pretreated with $3 \mu \mathrm{M}$ PMSF-inactivated HLE before LPS challenge.
The same experiments were conducted with a higher concentration of LPS, i.e., $10 \mu \mathrm{g} / \mathrm{ml}$ (Figure $8 b$ ). This resulted in an increase of the inflammatory cytokine concentration in the supernatants compared with the amount released after stimulation by $1 \mathrm{ng} / \mathrm{ml}$ LPS. Under these conditions, pretreatment of monocytes for up to 30 minutes with $3 \mu \mathrm{M}$ HLE did not significantly change TNF- $\alpha$ release $(10.8 \pm 1.7$ vs. $13.1 \pm 0.9 \mathrm{pg} / \mu \mathrm{g}$ protein in the presence and absence of the neutrophil proteinase; $n=3, P>0.05$ ).

Different types of binding proteins and receptors are known to be involved in the specific interaction and activation of monocytes by LPS (30). The possibility of more than one pathway for the induction of cytokine synthesis is admitted when cells are stimulated by high concentrations of LPS. By contrast, when low concentrations of LPS, such as $1 \mathrm{ng} / \mathrm{ml}$, are considered, only one pathway is likely to be involved, namely the CD14 pathway. In this case, activation of monocytes can be blocked by specific anti-CD14 antibodies (31). In agreement with this finding, our results showed differences in the ability of the specific monoclonal anti-CD14 antibody MY4 to inhibit activation of monocytes induced by a low or a high LPS concentration. Whereas MY4 was able to inhibit activation of monocytes initiated by $1 \mathrm{ng} / \mathrm{ml}$ LPS, as assessed by TNF- $\alpha$ accumulation (Figure $8 a$ ), this antibody was unable to affect this release upon cell stimulation by 10 $\mu \mathrm{g} / \mathrm{ml}$ LPS (Figure $8 b$ ). Note that a nonspecific control antibody, used at the same concentrations as MY4, did not show any inhibitory effects (Figure $8, a$ and $b$ ). Hence, these data indicate that treatment of monocytes with HLE specifically suppressed the CD14-dependent cell activation pathway triggered by LPS.

\section{Discussion}

The present study demonstrates a downregulatory effect of a PMN enzyme, HLE, on the membrane expression of CD14, the main bacterial LPS receptor at the surface of monocytes (21). This event depends on the enzymatic activity of the PMN proteinase but is independent of monocyte activation. Our investigation clearly demonstrated a direct and extensive proteolytic effect of HLE on membrane CD14, associated with the consequent release of multiple CD14 fragments into the extracellular medium. 
$a$

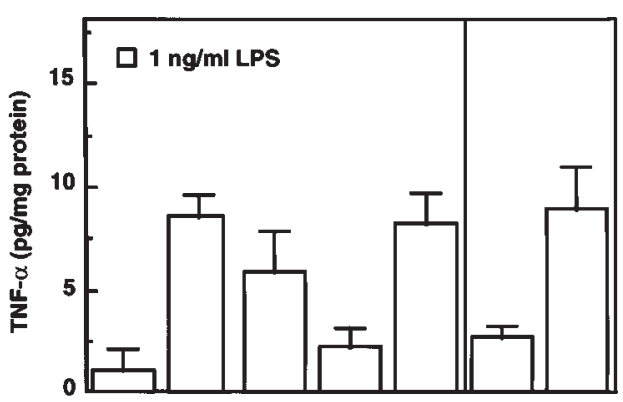

$b$

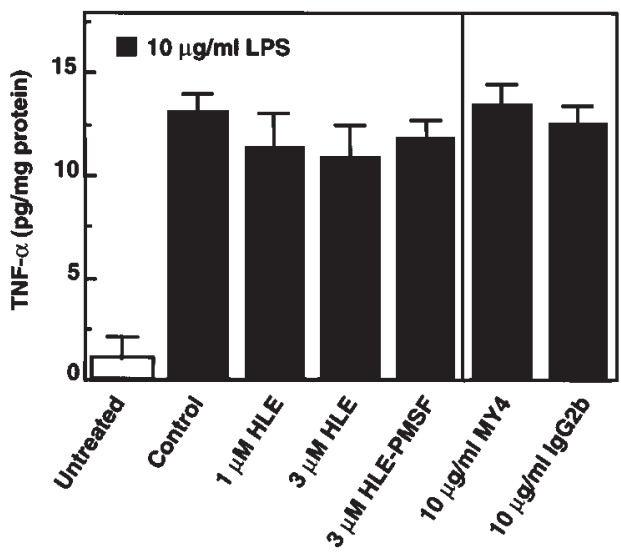

Figure 8

Inhibition by HLE of TNF- $\alpha$ synthesis by LPS-activated human monocytes. Monocytes were preincubated as indicated under each column for $30 \mathrm{~min}$ at $37^{\circ} \mathrm{C}$, and reactions were stopped by $20 \mu \mathrm{M}$ eglin C. Cells were then washed twice with medium before stimulation with $(\boldsymbol{a}) 1 \mathrm{ng} / \mathrm{ml}$ or (b) $10 \mu \mathrm{g} / \mathrm{ml}$ LPS for $3 \mathrm{~h}$ at $37^{\circ} \mathrm{C}$. Supernatants were analyzed for TNF$\alpha$ content by ELISA. Data represent means \pm SEM of three experiments with cells from different donors. LPS, lipopolysaccharide; TNF- $\alpha$, tumor necrosis factor- $\alpha$.

Such a proteolysis of cell surface-expressed molecules by HLE has been documented for other cell types. As an example for which mechanisms and specific cleavage sites have been delineated, our group has shown that this neutrophil enzyme proteolytically activates the platelet $\alpha_{\text {II }} \beta_{3}$ integrin through a cleavage at the $\mathrm{COOH}$-terminus of the $\alpha_{\text {IIb }}$ subunit (26). In addition, we have reported the specific inhibition of the thrombin serpentine receptor through two cleavages in the $\mathrm{NH}_{2}$-terminal extracellular domain (14). In both cases, a major peptidic part of the molecule remained associated with the cell membrane. Concerning CD14, our present data suggest that the entire peptidic portion, or at least a very large portion of CD14, is removed from the monocyte cell surface. This was evidenced by immunoblot analysis using a polyclonal antiCD14 antibody that failed to identify any membranebound proteolytic fragments in cell lysates from HLE-treated monocytes. Furthermore, CD14 is remarkably susceptible to proteolysis by HLE. Indeed, we were unable to detect immunoreactive material in the extracellular medium, a result likely due to the formation of numerous small fragments that suggest the presence of a large number of proteolytic sites. This was supported by experiments using soluble recombinant CD14, which upon incubation with HLE generated fragments that were barely discernible by immunoblot analysis. This feature is very different from the physiological downregulation of CD14 expression mediated by endogenous enzymes released upon activation of monocytes by several agonists, which give rise to a single shed fragment with a molecular weight of 53,000 (22).

To our knowledge, this study constitutes the first demonstration of a CD14 proteolysis by HLE, previous investigations having only studied an effect of trypsin, a related serine proteinase. Thus, Corrales et al. (32) demonstrated that the treatment of monocytes with concentrations of trypsin above $2 \mu \mathrm{M}$ resulted in a reduction of CD14 expression. In contrast, two other studies established that CD14 was relatively resistant to digestion by trypsin $(33,34)$. These latter observations may thus indicate a unique property of HLE. However, McGinley et al. (33) noted that chymotrypsin (as opposed to trypsin) was efficient and generated several moderately sized peptides. This may indicate a potential effect of another serine proteinase released from activated PMNs along with HLE, namely cathepsin G. This is a chymotrypsin-like enzyme that has also been shown to proteolyse like HLE, but through distinct sites of cleavage, different cell-surface molecules such as the Ib $\alpha$ subunit of the platelet glycoprotein Ib-V-IX complex (35), and the endothelial or platelet thrombin serpentine receptor (14).

Monocyte activation is a major event in the host immune response to LPS from Gram-negative bacteria. Upon stimulation with LPS, monocytes exhibit marked morphologic changes, enhanced phagocytic capacity, and increased bactericidal activity, a multiplicity of events beneficial for the host. Concomitantly, they release a plethora of mediators participating in the inflammatory process (36). Activation of these phagocytes through CD14 leads to the activation of a number of intracellular protein kinases. In particular, a protein tyrosine kinase-dependent pathway is triggered, inducing activation of the nuclear transcription factor NF- $\mathrm{KB}$ (37). This transcription factor regulates a broad set of genes encoding inflammatory molecules $(38)$ such as TNF- $\alpha(39,40)$. TNF- $\alpha$ is a key cytokine in septic shock as shown in several experimental models (41). It was, therefore, of great importance that our study demonstrated that a major consequence of the proteolysis of CD14 by HLE is a significant inhibition of TNF- $\alpha$ synthesis by monocytes. Thus, we observed that TNF- $\alpha$ formation was suppressed when LPS activated monocytes through CD14 (see below). We have also established that there was a good correlation between the extent of the downregulation of CD14 cell-surface expression and the inhibition of TNF$\alpha$ synthesis at 1 and $3 \mu \mathrm{M}$ HLE, respectively. In that context, note that it was previously shown that HLE proteolytically inactivates TNF- $\alpha$ per se (42) and cleaves the p75 TNF receptor (19). Consequently, the present investigation adds another original and major mechanism to downregulate TNF- $\alpha$ participation in the inflammatory process. In a larger context, the modulation of CD14 expression by HLE implies an inhibition of the overall CD14-mediated signal transduction pathways with the suppression of the upregulation of a broad set of proinflammatory factors. However, the inhibition of LPSinduced TNF- $\alpha$ synthesis by HLE was only observed under specific conditions, i.e., when low concentrations 
of LPS stimulate monocytes. The rationale is that high LPS concentrations induce gene expression and cytokine production via a CD14-independent pathway (43). Indeed, under these conditions monocyte activation by LPS is known to result from interactions with molecules distinct from CD14, including the $\beta 2$ integrins CD11b/CD18 and CD11c/CD18 (43), a 73-kDa protein (30), or L-selectin (44). In the present study, such a CD14independent activation by LPS has been depicted using the monoclonal anti-CD14 blocking antibody MY4. Thus, in agreement with previous work (31), MY4 prevented the response of monocytes to $1 \mathrm{ng} / \mathrm{ml} \mathrm{LPS} \mathrm{in}$ terms of TNF- $\alpha$ release, but this inhibition was overcome by using $10 \mu \mathrm{g} / \mathrm{ml}$ of LPS. In that respect, it was crucial that pretreatment by HLE gave similar results. This, therefore, strongly argues that the site of action of HLE on LPS activation of human monocytes is specifically limited to the CD14 pathway.

Very recently it has been demonstrated that CD14 might mediate LPS-induced cell activation through interactions with the Toll-like receptor 2 (TLR2) $(45,46)$. This molecule would be the long-sought-for transmembrane receptor bridging the GPI-anchored CD14 and intracellular signal transducing molecules (47). As a consequence, HLE-induced inhibition of TNF- $\alpha$ synthesis might also be due to a cleavage of TLR2. However, two observations rule out this possibility. First, we observed a fairly good correlation between the proteolysis of CD14 by HLE and the inhibition of TNF- $\alpha$ synthesis (Figures 1 and 8). More importantly, TLR2 is activated by LPS in the presence of CD14, but when this latter molecule is lacking, TLR2 can still be activated as long as higher concentrations of LPS are used $(45,46)$. This is consistent with our current findings. Indeed, and as already mentioned, HLE treatment or the presence of the CD14-blocking antibody MY4 precludes monocyte responsiveness to 1 $\mathrm{ng} / \mathrm{ml}$ LPS (i.e., by inference) - when TLR2 needs CD14 to operate intracellular signaling - but not to $10 \mu \mathrm{g} / \mathrm{ml}$ LPS, when TLR2 can signal by itself, independent of CD14. From these considerations, one can conceive that a proteolysis of TLR2 is doubtful, and if effective, it is not of functional significance, leaving the cleavage of the CD14 molecule per se accountable for the inhibition of TNF- $\alpha$ synthesis upon HLE pretreatment.

The present data establish that PMN-derived HLE may contribute to inhibit LPS-mediated inflammation. This can be extended to other pathogen-derived molecules known to interact with CD14, including lipoteichoic acid (48) and peptidoglycans from Gram-positive bacteria (49) and lipoarabinomannan from mycobacteria (50). These interactions also lead to cell activation. In addition, the downregulatory effect of HLE is likely to occur in vivo. Indeed, we previously evaluated that at the physiological blood concentration, activated PMNs may release up to $380 \mathrm{nM}$ HLE into the surrounding medium (51). It is known that under certain acute inflammatory conditions, the concentration of PMNs may increase by 14-fold in the peripheral circulation and even by 100 -fold at inflammatory foci $(52,53)$. This suggests that in a confined injuredtissue environment, much higher concentrations of HLE may be reached. As an example, concentrations of free catalytically active HLE in the epithelial lining fluid of patients with cystic fibrosis range from 1 to $80 \mu \mathrm{M}$ with demonstrable elastolytic activity (54). These enzymatic concentrations are well above the concentrations needed for CD14 proteolysis, even if one considers the presence of the surrounding antiproteinase screen. In fact, at inflammatory sites, close contacts between monocytes and PMNs may create a microenvironment that protects proteinases from their inhibitors. In addition, a recent study demonstrated a quantum release by PMNs of their azurophilic granule, resulting in pericellular concentrations of HLE approximately two orders of magnitude greater than the physiological concentrations of the proteinase inhibitors (55). In support of the assumption that some free, active HLE is present in the circulation, it is important to mention that an HLE-specific fibrinopeptide is found in plasma of cigarette smokers and of individuals with specific pathologies (56). Regardless, to our knowledge our study is the first to establish a direct proteolysis of the membrane CD14 expressed on monocytes by HLE and to illustrate a potential anti-inflammatory effect of this PMN-derived enzyme through inhibition of LPS-mediated cell activation.

\section{Acknowledgments}

The authors wish to thank Dominique Pidard (Institut National de la Santé et de la Recherche Médicale 485, Institut Pasteur) for critically reading the manuscript. K. Le-Barillec was supported by a grant from Délégation Générale pour l'Armement.

1. Smith, J.A. 1994. Neutrophils, host defense, and inflammation: a double-edged sword. J. Lenkoc. Biol. 56:672-686.

2. Woessner, J.F., Jr. 1992. Role of cellular proteinases and their protein inhibitors in inflammation. In Biochemistry of inflammation. J.T. Whicher and S.W. Evans, editors. Kluwer Academic Publishers. Lancaster, PA. 57-89.

3. Döring, G. 1994. The role of neutrophil elastase in chronic inflammation. Am. J. Respir. Crit. Care Med. 150:S114-S117.

4. Travis, J., Pike, R., Imamura, T., and Potempa, J. 1994. The role of proteolytic enzymes in the development of pulmonary emphysema and periodontal disease. Am. J. Respir. Crit. Care Med. 150:S143-S146.

5. Bieth, J.G. 1986. Elastases: catalytic and biological properties. In Regulation of matrix accumulation. R. Mecham, editor. Academic Press. New York, NY. 217-230.

6. Peterson, M.W., Stone, P., and Shasby, D.M. 1987. Cationic neutrophil proteins increase transendothelial albumin movement. J. Appl. Physiol. 62:1521-1530.

7. Peterson, M.W., Walter, M.E., and Nygaard, S.D. 1995. Effect of neutrophil mediators on epithelial permeability. Am. J. Respir. Cell Mol. Biol. 13:719-727.

8. Smedly, L.A., et al. 1986. Neutrophil-mediated injury to endothelial cells: enhancement by endotoxin and essential role of neutrophil elastase. $J$. Clin. Invest. 77:1233-1243.

9. Nahori, M.A., Renesto, P., Vargaftig, B.B., and Chignard, M. 1992. Activation and damage of cultured airway epithelial cells by human elastase and cathepsin G. Eur. J. Pharmacol. 228:213-218.

10. Sommerhoff, C.P., Nadel, J.A., Basbaum, C.B., and Caughey, G.H. 1990. Neutrophil elastase and cathepsin G stimulate secretion from cultured bovine airway gland cells. J. Clin. Invest. 85:682-689.

11. Bedard, M., et al. 1993. Release of interleukin-8, interleukin-6, and colony-stimulating factors by upper airway epithelial cells: implications for cystic fibrosis. Am. J. Respir. Cell Mol. Biol. 9:455-462.

12. Nakamura, H., Yoshimura, K., McElvaney, N.G., and Crystal, R.G. 1992. Neutrophil elastase in respiratory epithelial lining fluid of individuals with cystic fibrosis induces interleukin-8 gene expression in a human bronchial epithelial cell line. J. Clin. Invest. 89:1478-1484.

13. Cai, T.Q., and Wright, S.D. 1996. Human leukocyte elastase is an endogenous ligand for the integrin CR3 (CD11b/CD18, Mac-1, $\alpha_{M} \beta_{2}$ ) and modulates polymorphonuclear leukocyte adhesion. J. Exp. Med. 184:1213-1223.

14. Renesto, P., et al. 1997. Specific inhibition of thrombin-induced cell activation by the neutrophil proteinases elastase, cathepsin G, and proteinase 3: evidence for distinct cleavage sites within the amino terminal domain of the thrombin receptor. Blood. 89:1944-1953.

15. Cirino, G., et al. 1996. Thrombin functions as an inflammatory media- 
tor through activation of its receptor. J. Exp. Med. 183:821-827.

16. Döring, G., et al. 1995. Cleavage of lymphocyte surface antigens CD2, CD4 and CD8 by polymorphonuclear leukocyte elastase and cathepsin $\mathrm{G}$ in patients with cystic fibrosis. J. Immunol. 154:4842-4850.

17. Tosi, M.F., and Zakem, H. 1992. Surface expression of Fc $\gamma$ receptor III (CD16) on chemoattractant-stimulated neutrophils is determined by both surface shedding and translocation from intracellular storage compartments. J. Clin. Invest. 90:462-470.

18. Remold-O'Donnell, E., and Parent, D. 1995. Specific sensitivity of CD43 to neutrophil elastase. Blood. 86:2395-2402.

19. Porteu, F., Brockhaus, M., Wallach, D., Engelmann, H., and Nathan, C.F. 1991. Human neutrophil elastase releases a ligand-binding fragment from the $75-\mathrm{kDa}$ tumor necrosis factor (TNF) receptor. J. Biol. Chem. 266:18846-18853.

20. Van Rooijen, N., and Sanders, A. 1997. Elimination, blocking, and activation of macrophages: three of a kind? J. Leukoc. Biol. 62:702-709.

21. Wright, S.D., Ramos, R.A., Tobias, P.S., Ulevitch, R.J., and Mathison, J.C. 1990. CD14, a receptor for complexes of lipopolysaccharide (LPS) and LPS binding protein. Science. 249:1431-1433.

22. Campbell, E.J. 1982. Human leukocyte elastase, cathepsin G, and lactoferrin: family of neutrophil granule glycoproteins that bind to an alveolar macrophage receptor. Proc. Natl. Acad. Sci. USA. 79:6941-6945.

23. Bazil, V., and Strominger, J.L. 1991. Shedding as a mechanism of downmodulation of CD14 on stimulated human monocytes. J. Immunol. 147:1567-1574.

24. Si-Tahar, M., Renesto, P., Falet, H., Rendu, F., and Chignard, M. 1996. The phospholipase $\mathrm{C} /$ protein kinase $\mathrm{C}$ pathway is involved in cathepsin G-induced human platelet activation: comparison with thrombin. Biochem. J. 313:401-408.

25. Azevedo, I., et al. 1997. Increased spontaneous release of tumour necrosis factor- $\alpha$ by alveolar macrophages from wheezy infants. Eur. Respir. J. 10:1767-1773.

26. Si-Tahar, M., et al. 1997. Human neutrophil elastase proteolytically activates the platelet integrin $\alpha_{\mathrm{II}} \beta_{3}$ through cleavage of the carboxyl terminus of the $\alpha_{\text {IIb }}$ subunit heavy chain. J. Biol. Chem. 272:11636-11647.

27. Laemmli, U.K. 1970. Cleavage of structural proteins during the assembly of the head of bacteriophage T4. Nature. 227:680-685.

28. Haziot, A., et al. 1988. The monocyte differentiation antigen, CD14, is anchored to the cell membrane by a phosphatidylinositol linkage. $J$. Immunol. 141:547-552.

29. Eigler, A., Sinha, B., Hartmann, G., and Endres, S. 1997. Taming TNF: strategies to restain this proinflammatory cytokine. Immunol. Today. 18:487-492.

30. Rietschel, E.T., et al. 1996. Bacterial endotoxin: chemical constitution, biological recognition, host response, and immunological detoxification. Curr. Top. Microbiol. Immunol. 216:39-81.

31. Lynn, W.A., Liu, Y., and Golenbock, D.T. 1993. Neither CD14 nor serum is absolutely necessary for activation of mononuclear phagocytes by bacterial lipopolysaccharide. Infect. Immun. 61:4452-4461.

32. Corrales, I., Weersink, A.J.L., Verhoef, J., and Van Kessel, K.P.M. 1993. Serum-independent binding of lipopolysaccharide to human monocytes is trypsin sensitive and does not involve CD14. Immunology. 80:84-89.

33. McGinley, M., et al. 1995. CD14: physical properties and identification of an exposed site that is protected by lipopolysaccharide. J. Biol. Chem. 270:5213-5218.

34. Vasselon, T., Pironkova, R., and Detmers, P. 1997. Sensitive responses of leukocytes to lipopolysaccharide require a protein distinct from CD14 at the cell surface. J. Immunol. 159:4498-4505.

35. Pidard, D., et al. 1994. Neutrophil proteinase cathepsin G is proteolytically active on the human platelet glycoprotein Ib-IX receptor: charac- terization of the cleavage sites within the glycoprotein Ib $\alpha$ subunit. Biochem. J. 303:489-498.

36. Laskin, D.L., and Pendino, K.J. 1995. Macrophages and inflammatory mediators in tissue injury. Annu. Rev. Pharmacol. Toxicol. 35:655-677.

37. Sweet, M.J., and Hume, D.A. 1996. Endotoxin signal transduction in macrophages. J. Leukoc. Biol. 60:8-26.

38. May, M.J., and Ghosh, S. 1998. Signal transduction through NF-кB. Immunol. Today. 19:80-88.

39. Collart, M.A., Baeuerle, P., and Vassalli, P. 1990. Regulation of tumor necrosis factor alpha transcription in macrophages: involvement of four $\kappa \mathrm{B}$-like motifs and of constitutive and inducible forms of NF-кB. Mol. Cell. Biol. 10:1498-1506.

40. Shakhov, A.N., Collart, M.A., Vassalli, P., Nedospasov, S.A., and Jongeneel, C.V. 1990. $\mathrm{\kappa B}$-type enhancers are involved in lipopolysaccharidemediated transcriptional activation of the tumor necrosis factor $\alpha$ gene in primary macrophages. J. Exp. Med. 171:35-47.

41. Volk, H.D., et al. 1996. Monocyte deactivation-rationale for a new therapeutic strategy in sepsis. Intensive Care Med. 22:S474-S481.

42. Scuderi, P., Nez, P.A., Duerr, M.L., Wong, B.J., and Valdez, C.M. 1991. Cathepsin-G and leukocyte elastase inactivate human tumor necrosis factor and lymphotoxin. Cell. Immunol. 135:299-313.

43. Medvedev, A.E., et al. 1998. Involvement of CD14 and complement receptors CR3 and CR4 in nuclear factor- $\mathrm{\kappa B}$ activation and TNF production induced by lipopolysaccharide and group B streptococcal cell walls. J. Immunol. 160:4535-4542.

44. Malhotra, R., and Bird, M.I. 1997. L-selectin - a signalling receptor for lipopolysaccharide. Chem. Biol. 4:543-547.

45. Yang, R.-B., et al. 1998. Toll-like receptor-2 mediates lipopolysaccharideinduced cellular signalling. Nature. 395:284-288.

46. Kirschning, C.J., Wesche, H., Ayres, T.M., and Rothe, M. 1998. Human Toll-like receptor 2 confers responsiveness to bacterial lipopolysaccharide. J. Exp. Med. 188:2091-2097.

47. Ulevitch, R.J., and Tobias, P.S. 1995. Receptor-dependent mechanisms of cell stimulation by bacterial endotoxin. Annu. Rev. Immunol. 13:437-457.

48. Cleveland, M.G., Gorham, J.D., Murphy, T.L., Tuomanen, E., and Murphy, K.M. 1996. Lipoteichoic acid preparations of Gram-positive bacteria induce interleukin-12 through a CD14-dependent pathway. Infect. Immun. 64:1906-1912

49. Gupta, D., Kirkland, T.N., Viriyakosol, S., and Dziarski, R. 1996. CD14 is a cell-activating receptor for bacterial peptidoglycan. J. Biol. Chem. 271:23310-23316.

50. Pugin, J., et al. 1994. CD14 is a pattern recognition receptor. Immunity. 1:509-516.

51. Renesto, P., and Chignard, M. 1993. Enhancement of cathepsin Ginduced platelet activation by leukocyte elastase: consequence for the neutrophil-mediated platelet activation. Blood. 82:139-144.

52. Hehrer, R.I., Ganz, T., Selsted, M.E., Babior, B.M., and Curnutte, J.T. 1987. Neutrophils and host defense. Ann. Intern. Med. 107:526-545.

53. Colditz, I.G. 1987. Early accumulation of neutrophils in acute inflammatory lesions. In Leukocyte emigration and its sequelae. H.Z. Movat, editor. Karger Press. Basel, Switzerland. 14-23.

54. Vender, R.L. 1996. Therapeutic potential of neutrophil-elastase inhibition in pulmonary disease. J. Investig. Med. 44:531-539.

55. Liou T.G., and Campbell, E.J. 1996. Quantum proteolysis resulting from release of single granules by human neutrophils. A novel, nonoxidative mechanism of extracellular proteolytic activity. J. Immunol. 157:2624-2631.

56. Weitz, J.I., Silverman, E.K., Thong, B., and Campbell, E.J. 1992. Plasma levels of elastase-specific fibrinopeptides correlate with proteinase inhibitor phenotype. J. Clin. Invest. 89:766-773. 